\title{
Preparedness Measures for Emergency and Disaster Response
}

\author{
Tobias Andersson Granberg
}

\section{Linköping University Post Print}

\section{Tweet}

N.B.: When citing this work, cite the original article.

Original Publication:

Tobias Andersson Granberg, Preparedness Measures for Emergency and Disaster Response, 2013, Humanitarian and Relief Logistics: Research Issues, Case Studies and Future Trends, $59-75$.

http://dx.doi.org/10.1007/978-1-4614-7007-6_4

Copyright: Springer

http://link.springer.com/

Postprint available at: Linköping University Electronic Press

http://urn.kb.se/resolve?urn=urn:nbn:se:liu:diva-93652 


\title{
Preparedness measures for emergency and disaster response
}

\author{
Tobias Andersson Granberg
}

Division of Communication and Transport Systems Linköping University, ITN, SE-60174 Norrköping

tobias.andersson@liu.se,+46-11-363213

\begin{abstract}
Quantitative preparedness measures can be used to calculate the level of preparedness for handling disasters or emergencies. They are useful for evaluating plans and preparations, and for comparing areas and organizations with each other. This chapter gives an introduction to the construction and use of such measures, and proposes a general methodology that can be applied when developing them. The methodology is exemplified on two case studies, the first concerning disaster preparedness, and the second daily events. In the first case study, a hurricane disaster risk index is developed to compare the preparedness for handling hurricanes in different counties. The second case study describes the development and validation of a preparedness measure for emergency medical services, which is used to support decisions about ambulance dispatch and relocation.
\end{abstract}

\section{Introduction}

\subsection{Background}

If you ask one ambulance dispatcher about the current preparedness in the area, he or she might answer that it is good, everything is under control. If you ask another dispatcher the same thing, for the same area, the same time, he or she may say that the situation is strained, the preparedness is low, additional resources may need to be called in. Two different people may conceive a situation differently, even if they are both professionals. 
Furthermore, since no accepted and utilized definition of emergency medical preparedness exist, both of them are right (Andersson et al. 2007).

In the example above, both ambulance dispatchers will have an opinion considering the preparedness, even though they might not agree on the specifics. The dispatchers know that emergency medical preparedness is a description of the ability to serve people in need of out of hospital medical care now and in the future. There are relatively few factors that affect this preparedness, the most obvious being the number of available ambulances (and the expected number of available ambulances in future) together with their expected response times, and the expected call frequency.

When considering preparedness for more severe events, the situation becomes more complex. If you were to ask somebody in the crisis management organization for an arbitrary municipality to describe the state of the municipality's disaster preparedness, there is a good chance that the answer would be "I don't know". If you ask somebody which of two cities that has the best preparedness for handling a major storm or a severe act of terrorism, the answer might evolve to "I have absolutely no idea" (Simpson 2008).

It is more difficult to define what encompasses disaster preparedness than emergency medical preparedness, since many more factors affect the disaster preparedness. Factors for handling a major storm would for example include response resources like fire and rescue services, ambulances and police, available disaster plans and crisis management organizations, alarm systems and many more. Also, some sort of measure of the risk that a major storm will occur, and the magnitude of the storm is needed.

Thus, it is not trivial to define, and perhaps even more difficult to quantify, the concept of preparedness. Still, it is - or at least should be - necessary when making plans and constructing methods for emergency and disaster response and management. If you can measure the preparedness, it will give you an indication of how prepared you are for handling a certain type of event. If you cannot measure the preparedness, it will be more difficult to assess the potential impact of an event, or to compare different plans, systems or solutions with each other. 


\subsection{Chapter purpose and outline}

The purpose of this chapter is to introduce the concept of quantitative preparedness measures, and suggest a general methodology for constructing such measures. The next sub section will go through a number of definitions and expressions related to preparedness measures. While not aiming to review all the related literature, Section 1.4 will give a few examples of case studies, projects and initiatives where some sort of preparedness measures are constructed or used.

In Section 2, a general methodology for constructing a preparedness measure is presented. This methodology is then exemplified in Section 3, where it is applied on two cases studies (which were carried out before the development of the general methodology). The first case study, described in Section 3.1 is performed by Davidson and Lambert (2001). The second, described in Section 3.2, is partly an original contribution to this chapter, although some of the contents have been previously published in Andersson et al. (2007) and Andersson and Värbrand (2007).

This chapter ends with Section 4, which contains conclusions and some recommendations for further studies.

\subsection{Preparedness definitions}

There exists no general definition of preparedness that is useful for actually evaluating the preparedness in a certain situation. One example of a general definition is "the state of being prepared or ready, esp militarily ready for war" (Collins English Dictionary 2003), which does not tell us anything of what is needed for the preparedness to be high or low, good or bad. A definition from the secretariat of the International Strategy for Disaster Reduction (UNISDR 2011) states that preparedness is "The knowledge and capacities developed by governments, professional response and recovery organizations, communities and individuals to effectively anticipate, respond to, and recover from, the impacts of likely, imminent or current hazard events or conditions.” This gives some clues 
to which resources that might be necessary, and highlights that preparedness may be viewed from different perspectives, but we still need to know the details regarding the incidents.

For a preparedness measure to be useful, it is necessary to define the event you would like to be prepared for, as well as the perspective from which the measure will be used. Two examples of more practically useful definitions are "Tsunami preparedness refers to an individual's perception of the extent of being prepared to confront with future tsunami." (Rachmalia et al. 2011) and "Strategic preparedness connotes a set of policies, plans, and supporting infrastructure that is implemented in advance of a natural or man-made disaster." (Haimes et al. 2008). In the latter case however, the policies and plans will vary significantly if the disaster is flood or if it is a train bombing.

Preparedness measures and indicators are used to evaluate the situation before an emergency or a disaster has occurred. Depending on the event under consideration, different factors will affect the preparedness. It is also possible to view preparedness from different perspectives, e.g.:

- Personal preparedness. A person's or a household's preparedness for handling a certain type of event.

- Organizational preparedness. A response organization, e.g. the police, might be interested in the preparedness for helping people, while a company may have their own preparedness for dealing with disasters, emergencies or economic crises.

- Society preparedness. On a larger scale, society preparedness can be a nation's ability to handle a major disaster, i.e. national disaster preparedness. On a regional scale, it may be a measure of how the region, e.g. a county or a municipality, is organized to ensure the safety and security of its inhabitants in case of accidents.

Risk, hazard and vulnerability are concepts that are closely related to preparedness. They share a characteristic in that there exist no universal - but a multitude - of definitions for each expression. 
Once again falling back the UNISDR definitions (UNISDR 2011), they state that:

- Hazard is “A dangerous phenomenon, substance, human activity or condition that may cause loss of life, injury or other health impacts, property damage, loss of livelihoods and services, social and economic disruption, or environmental damage.”

- Vulnerability is "The characteristics and circumstances of a community, system or asset that make it susceptible to the damaging effects of a hazard."

- Risk is "The combination of the probability of an event and its negative consequences.”

Thus, an earthquake is a hazard, and the hazard probability in an area together with a measure of the potential negative consequences (which are directly dependent on the vulnerability), make up the risk. Furthermore, it is argued that vulnerability must be discussed within a hazard context, and that response and recovery constitutes important parts of the vulnerability (Birkmann 2007). That is, an area with plenty of emergency response resources is less vulnerable to a forest fire, than a similar area with fewer resources. Measuring risk and vulnerability is similar to measuring preparedness, and in some cases it can easily be argued that a preparedness measure could be denominated a vulnerability measure or a risk measure.

\subsection{Relevant work}

Table 1.1 summarizes a number of studies where preparedness (or in some cases risk or vulnerability) measures are developed. More examples of work done to measure the risk, vulnerability and preparedness for disasters can be found in Birkmann (2007). Similar studies regarding everyday emergencies are scarcer; in Table 1.1, only Andersson and Värbrand (2007) clearly focus on routine emergencies, although it may be possible to view the road tunnel accidents considered in Manca and Brambilla (2011) as less severe emergencies as well. 
Table 1.1. Event and perspective for some preparedness measure studies

\begin{tabular}{|c|c|c|c|}
\hline Source & Event & Perspective & Purpose of measure \\
\hline $\begin{array}{l}\text { Andersson and } \\
\text { Värbrand (2007) }\end{array}$ & $\begin{array}{l}\text { Routine ambu- } \\
\text { lance calls }\end{array}$ & Organizational & $\begin{array}{l}\text { Calculate preparedness levels } \\
\text { within a county to support dis- } \\
\text { patching and relocation }\end{array}$ \\
\hline Baker (2011) & Hurricanes & Personal & $\begin{array}{l}\text { Analyze household preparedness, } \\
\text { to find relationships between pre- } \\
\text { paredness and demographic vari- } \\
\text { ables, and between preparedness } \\
\text { and demand for relief materials }\end{array}$ \\
\hline Cardona (2005) & $\begin{array}{l}\text { General disas- } \\
\text { ter }\end{array}$ & Society & $\begin{array}{l}\text { To compare the disaster prepar- } \\
\text { edness between countries }\end{array}$ \\
\hline $\begin{array}{l}\text { Davidson and } \\
\text { Lambert (2001) }\end{array}$ & Hurricanes & Society & $\begin{array}{l}\text { To compare in U.S. counties' } \\
\text { preparedness for handling hurri- } \\
\text { canes }\end{array}$ \\
\hline $\begin{array}{l}\text { Manca and Bram- } \\
\text { billa (2011) }\end{array}$ & $\begin{array}{l}\text { Road tunnel } \\
\text { accidents }\end{array}$ & $\begin{array}{l}\text { Society, organi- } \\
\text { zational }\end{array}$ & $\begin{array}{l}\text { Evaluate tunnel safety by compar- } \\
\text { ing it to an optimum level }\end{array}$ \\
\hline $\begin{array}{l}\text { Markenson and } \\
\text { Krug (2009) }\end{array}$ & $\begin{array}{l}\text { Pediatric care } \\
\text { in case of gen- } \\
\text { eral disaster }\end{array}$ & Organizational & $\begin{array}{l}\text { No specific measure developed: } \\
\text { discussion and recommendations }\end{array}$ \\
\hline $\begin{array}{l}\text { Rachmalia et al. } \\
\text { (2011) }\end{array}$ & Tsunami & Personal & $\begin{array}{l}\text { Analyze the relationship between } \\
\text { personal tsunami experience and } \\
\text { preparedness for a tsunami }\end{array}$ \\
\hline Simpson (2008) & $\begin{array}{l}\text { General disas- } \\
\text { ter }\end{array}$ & Society & $\begin{array}{l}\text { To compare the disaster prepar- } \\
\text { edness between cities }\end{array}$ \\
\hline WHO (2011) & $\begin{array}{l}\text { Pandemic in- } \\
\text { fluenza }\end{array}$ & Society & $\begin{array}{l}\text { To evaluate and compare differ- } \\
\text { ent countries' preparedness for } \\
\text { handling an influenza pandemic }\end{array}$ \\
\hline
\end{tabular}

The studies in Table 1.1 are classified according to Event, Perspective and Purpose of the measure. When the event is General disaster, this may mean that the measures in the study include multiple disasters, like in Cardona (2005) and Simpson (2008). Markenson and Krug (2009) do not develop a measure, but discuss pediatric care in the aftermath of events like 
hurricanes and terrorist attacks. The perspective (see Section 1.3) is selected based on the potential users and application of the measure. In Manca and Brambilla (2011), the perspective can be societal or organizational depending on who is responsible for the road tunnel safety. Most of the measures are used for comparing different areas (zones, cities, counties, countries) with each other. This is however often just one of the purposes; the comparison can then be used as a base for improving the preparedness.

\section{How to measure preparedness}

\subsection{Methodology}

A general methodology for constructing a preparedness measure is suggested below. It consists of four steps, each of which will be further discussed in the following sub sections:

1. Select event and perspective

2. Select indicators

3. Combine the indicators

4. Validate the measure

\subsection{Select event and perspective}

As described in Section 1.3, it is necessary to decide which event to prepare for, and which perspective that should be used. In many cases, this might be a straightforward decision. A response organization, like the fire and rescue services, should primarily be interested in the organizational preparedness, and the events that they are responsible for. However, if they want to construct a measure encompassing multiple events, e.g. the preparedness for handling all types of fires, traffic accidents, landslides and drowning accidents, the factors that need to be involved in the measure increases in number. It becomes even more complicated if you want to con- 
struct a measure for (general) disaster preparedness for a city. Then it is necessary to calculate the occurrence probability for all types of disasters that might affect the city. It is also necessary to select the perspective; in the society preparedness which is the natural choice for this example, the inclusion of both the organizational preparedness for the response organizations and the personal preparedness for the citizens might be required.

In short, the complexity of the preparedness measure rapidly increases with the number of events and the number of perspectives that the measure should be able to incorporate.

\subsection{Select indicators}

A preparedness measure is typically constructed by a set of indicators. A couple of examples of indicators that can be used for different kinds of events are:

- (Personal) tsunami preparedness: Knowledge, individual emergency planning and resource mobilization capacity (Rachmalia et al. 2011).

- (Personal) hurricane preparedness: Food for three days, flashlight with batteries for three days, medicines, drinkable water, important papers on hand, an outdoor grill, a generator (Baker 2011).

- (Organizational) road tunnel accident preparedness: tunnel length, emergency exists, tunnel manager experience, training of emergency personnel, first aid support, and many more (Manca and Brambilla 2011).

- (Organizational) pediatric emergency preparedness: pediatric providers available for emergency preparedness, specific numbers of pediatric patients who can be treated, number of children that the triage providers can triage per hour, etc. (Markenson and Krug (2009).

- (Society) national pandemic influenza preparedness: how often the national committee/task force meets, surveillance measures during 
a pandemic, health facilities priorities and response strategies, etc. (WHO 2001).

Furthermore, although they may not be directly used as preparedness measures, operations research methods applied to the preparations phase of disaster or emergency management usually have some criteria for evaluating proposed solutions. Some of these criteria may well be used as preparedness indicators, e.g. coverage measures, expected response times or satisfied demand.

When constructing a quantitative measure, it is necessary to use indicators that can be quantified. For instance, the indicator Knowledge, used in Rachmalia et al. (2011), was measured using a questionnaire where each respondent got a score depending on the level of knowledge. It is also necessary to select indicators for which reliable data is available, or possible to collect.

\subsection{Combine the indicators}

Assuming that there exist a set of sensible indicators, they will most probably vary significantly in units; including time measures, monetary units, binary units and percentages. If these indicators are to be combined into an index, or some other sort of measure, or if they are to be directly compared to each other, it may be necessary to weight or scale them. There are many methods for this, and a nice overview is given in Cardona (2005), where the advantages and disadvantages of methods like regression models, factor analysis, multi-criteria decision making, expert judgment, and analytic hierarchy process, among others, are discussed.

For a certain event or set of events and perspectives, it may not be enough to construct just one measure. It may even be contra productive for the intended purpose of the measure; e.g. creating a measure for all kinds of disasters that may affect a city can be useful if the main purpose is to compare different cities' disaster preparedness. It will however not necessarily give any guidelines as to how, and in which areas, the preparedness can be im- 
proved. For the latter purpose, one measure for each type of disaster that may affect the city would be more useful.

\subsection{Validate the measure}

When the selected indicators have been combined into a preparedness measure, it needs to be validated. A successful validation means that the measure fulfills its intended purpose. There are a number of methods and techniques available for validating quantitative models, and especially the validation of simulations models has been a thriving research area, see e.g. Sargent (2005). Although not all technics commonly used for validating simulation models are applicable here, a number of them can still be used to ensure that the developed measure produces reasonable and useful results.

Two examples of techniques mentioned in Sarget (2005), that can easily be applied to the validation of preparedness measures are:

- Sensitivity analysis: The parameters that constitute the input data to the measure are changed, and the output from the measure is studied. This is applied in the first case study (Section 3.1).

- Face validity: System experts are asked to study and comment the results produced by the measure. This is applied in the second case study (Section 3.2).

\section{Case studies}

Two cases studies are presented to illustrate how the proposed methodology can be used in practice. The first study concerns hurricane disasters, and is an example of a measure for disasters while the seconds study deals with emergency medical services concentrating on routine emergencies. It should be noted that the cases studies were performed before the development of the methodology. 


\subsection{Development of a hurricane disaster risk index}

In Davidson and Lambert (2001), a hurricane disaster risk index (HDRI) is developed for comparing the risk of hurricane disasters in counties in the U.S.A. The authors point out that they use the term hurricane disaster risk instead of hurricane risk, to make it clear that the response and recovery capability is included in the measure. Thus, it is quite possible to regard the index as a preparedness measure, since it also gives an indication on how prepared a county is for handling a hurricane.

\subsubsection{Selection of event and perspective}

The first step in the methodology described in Section 2 is to select the event and the perspective for the measure. The event type in this study is easily identified as a hurricane, i.e. a single specific event. The perspective should be regarded as societal, since the main intended purpose is to compare different counties.

\subsubsection{Selection of indicators}

The second step is to select appropriate indicators. Davidson and Lambert (2001) include four main factors in the study, each with a number of subfactors, which are made up by a number of indicators (see Table 3.1).

Table 3.1. Indicators for hurricane disaster risk used in Davidson and Lambert (2001)

\begin{tabular}{lll}
\hline \hline Factor & Subfactor & Indicator \\
\hline \multirow{3}{*}{ Hazard } & Wind hazard & Mean return period of hurricanes Cat 1-2 \\
\cline { 2 - 3 } & & Mean return period of hurricanes Cat 3-4 \\
\cline { 2 - 3 } & Storm surge & Mean return period of hurricanes Cat 5 \\
\cline { 2 - 3 } & Rainfall & Average forward speed of hurricanes [knots] \\
\hline \multirow{3}{*}{ Exposure } & Population expo- & Resident population \\
\cline { 2 - 3 } & sure & Average daily num. of tourists, June-Nov \\
\cline { 2 - 3 } & \multirow{2}{*}{ Building exposure } & Number of housing units \\
\cline { 2 - 3 } & & Median home value [dollars] \\
\hline
\end{tabular}




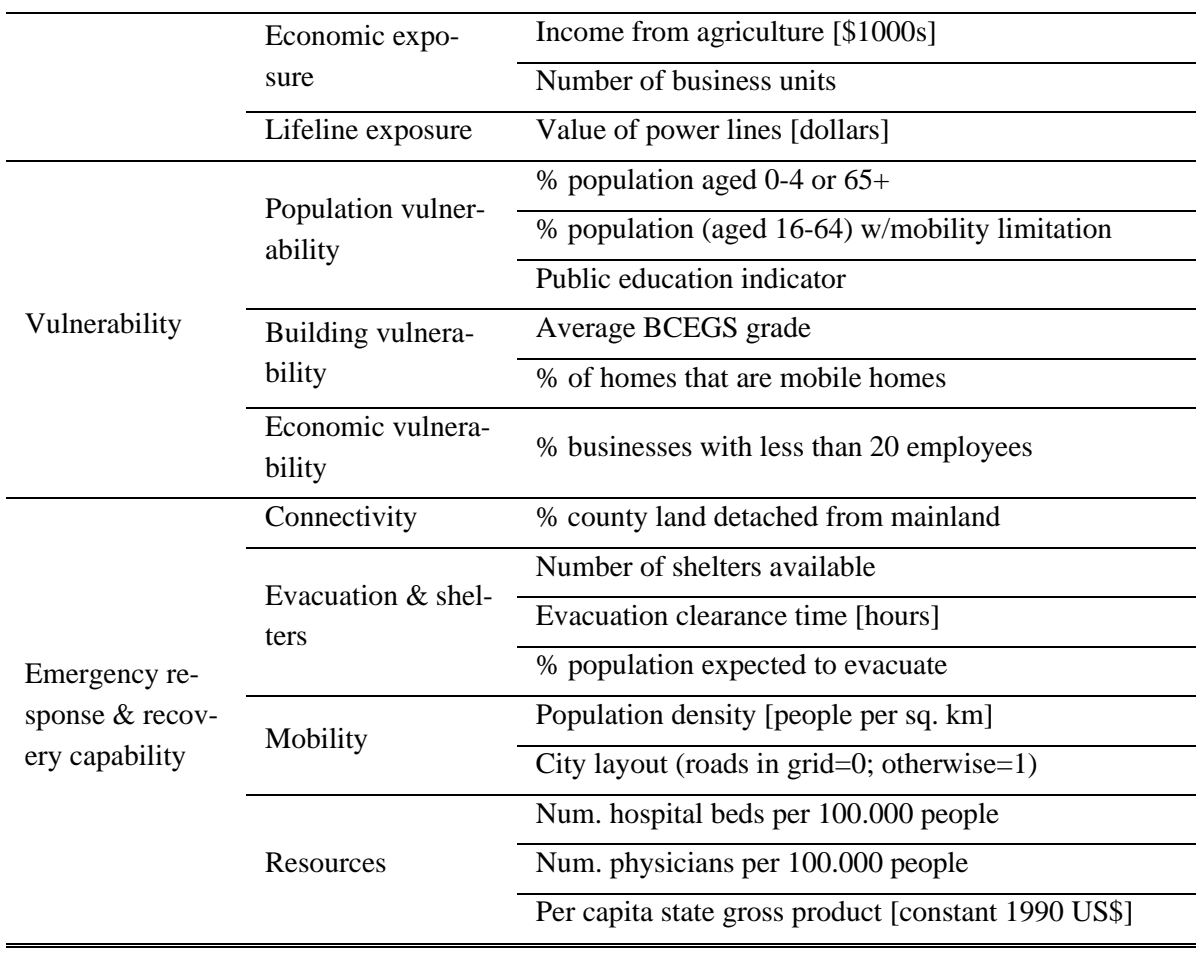

\subsubsection{Combining the indicators}

The third step is to combine the indicators to construct a measure that can be used to compare different counties. However, the indicators in Table 3.1 vary in units including knots, dollars and percentages. So, before the indicators are combined into an index, they are scaled using a linear function:

$X_{i j}=\frac{\left(X_{i j}^{\prime}-\text { minposs }_{i}\right) \times 10}{\left(\text { maxposs }_{i}-\text { minposs }_{i}\right)}$

where $X_{i j}$ ' is the unscaled value of indicator $i$ for county $j$. maxposs $s_{i}$ is the maximum expected value for the indicator that are likely to occur in any U.S. county in the next ten years, and minposs $s_{i}$ is the minimum expected value. However, for indicators that have a positive impact on the preparedness, minposs ${ }_{i}$ will have the larger value of the two. Thus, for the indicator Resident population, minposs is zero while maxposs is 2.3 million. 
Supposing a county has an unscaled indicator value of 750000 , the scaled value for the indicator will be $750000 \times 10 / 2300000=3.26$. The indicator Num. physicians per 100.000 people has a minposs of 690 and a maxposs of zero. Given that the unscaled indicator value is 150 , the scaled counterpart will become $(150-690) \times 10 /-690=7.82$. After scaling, the indicators take values from 0 to 10 , where less is good. A value close to zero for an indicator means that the risk is low, or that the preparedness is good, in regards to that specific indicator.

The indicators are then weighted and additively combined into a value for each factor, e.g. $\mathrm{V}=\mathrm{w}_{\mathrm{V} 1} \mathrm{X}_{\mathrm{V} 1}+\ldots+\mathrm{w}_{\mathrm{V} 6} \mathrm{X}_{\mathrm{V} 6}$, where $\mathrm{V}$ is the vulnerability factor and $\mathrm{w}_{\mathrm{V} 1}$ is the weight for the first vulnerability indicator (\% population aged $0-4$ or $65^{+}, \mathrm{X}_{\mathrm{V} 1}$ ). Finally the factors are multiplicatively combined into an index value with a weight for each factor. To determine the weights, the analytic hierarchy process is used, where the indicators are compared pairwise. Index values are calculated and analyzed for 15 U.S. counties.

\subsubsection{Validation of the measure}

The last step is to validate the measure, to make sure that the results are credible. Davidson and Lambert (2001) point out that

"Just as the indicator set is part of the definition of the concept that is being measured, so are the weight values. If the weights are changed, the concept being measured is also, and the county rankings corresponding to the new concept should not necessarily equal those associated with the original concept.”

That is, changing anything in the measure - indicators, parameters, or weights - might alter the results that the measure is used to produce. So, in order to analyze the results' sensitivity to changes in the weights, they perform an uncertainty analysis using Monte Carlo simulation, and conclude that the results are stable. The same type of validation is performed for uncertainty in input data, but here the results indicate that uncertainty in data 
might indeed affect the ranking of counties produced by the measure. Therefore, it may be beneficial to reduce data uncertainty.

In conclusion, the hurricane disaster risk index constructed by Davidson and Lambert (2001) is a nice example of a disaster preparedness measure that could well have been developed using methodology proposed in Section 2.

\subsection{An EMS preparedness index}

Keeping an adequate preparedness is one of the most complex tasks for an ambulance dispatcher. It requires knowledge of where call sites are likely to appear and of how fast the ambulances can travel through different parts of the area, as well as knowledge of where the ambulances currently are located and if they are available. Today, many ambulances have GPS (global positioning system) receivers and transmit their position and status to an emergency center. Still, to know where ambulances might be needed in the future, and how fast they can get there, requires experience. We will develop a preparedness measure for emergency medical services that can be used to support these decisions.

\subsubsection{Selection of event and perspective}

When selecting the event and the perspective for the measure (Step 1 of the methodology in Section 2), a definition for emergency medical services preparedness can be useful. A suggestion is that:

In emergency medical services, preparedness refers to the ability of being able to, within a reasonable time, offer qualified emergency medical care to the inhabitants in a specific geographical area.

The definition is purposely vague, leaving it to the politicians to decide how long time that is reasonable, and what qualified means. Still, it is possible to use as a base for building a preparedness index. 
The event in this case is any daily event that ambulances respond to, and the intended use for the measure is daily operations, i.e. routine emergencies. Here we assume that all events that ambulances respond to require just one ambulance, and that all ambulances in the system can be considered equally qualified to handle an event. Therefore, it is not necessary go into detail concerning the events, since they all require the same type and amount of resources. The perspective is organizational, since the intended users are ambulance dispatchers, who are responsible for maintaining the preparedness in a particular area.

\subsubsection{Selection of indicators}

In order to select indicators (Step 2), the geographical area is divided into a set of zones, $N$. A weight $c_{j}$ is assigned to each zone $j$. This weight mirrors the probability that an ambulance will be needed in the zone and can for example be calculated as $c_{j}=$ [the expected number of calls in zone $j$ ] where a forecast for the number of calls must be performed. It is also possible to base the weight on the population, advance knowledge of special events and other information that may affect the need for ambulances in the zone. The weights can also be time dependent, e.g. $c_{j t}=$ [the weight for zone $j$ in time period $t$ ], as the need for ambulances often varies with time. For simplicity, we will now however concentrate on static weights.

We assume that the preparedness in a zone mainly depends on three indicators:

1. The number of ambulances that can reach the zone (within a certain time).

2. The time it takes for the ambulances to reach the zone (i.e. the travel time).

3. The expected need for ambulances in the zone (i.e. $c_{j}$ ).

\subsubsection{Combining the indicators}

Using the three selected indicators, it is possible to construct a measure in a number of different ways. Depending on the construction, the different 
measures will have different qualities. This makes it important to carefully consider what the measure can and will be used for. The measure then has to be tested to see if it possesses the desired qualities.

The measure suggested here, is that the preparedness in a zone $j$ can be calculated as:

$p_{j}=\frac{1}{c_{j}} \sum_{l=1}^{L_{j}} \frac{\gamma}{t_{j}^{l}}$

where $c_{j}=$ the demand for zone $j$; $L_{j}=$ the number of ambulances that contribute to the preparedness in zone $j ; \gamma^{l}=$ the contribution factor (the weight) for ambulance $l$ ( $l=1$ is the closest, 2 the second closest etc.) and $t_{j}^{l}=$ the travel time to zone $j$ for ambulance $l$ and the following properties hold:

$t_{j}^{1} \leq t_{j}^{2} \leq \cdots \leq t_{j}^{L_{j}}$

$\gamma^{1}>\gamma^{2}>\cdots>\gamma^{j}$

Thus, the preparedness is calculated by letting the $L_{j}$ closest ambulances to zone $j$ contribute to the preparedness with an impact that is decreasing as the travel time to the zone increases.

The basic idea behind the measure is that the closest ambulance is the most important and therefore should give the largest contribution to the preparedness. More ambulances than one might however be needed to ensure a high preparedness. If the demand $c_{j}$ is large, this indicates that the frequency of calls in the zone is relatively high, which means that one ambulance probably will not be able to serve one call and become available again before the next call arrives. In this case there is a need for backup ambulances in, or close to, the zone to ensure that the preparedness does not drop to an unacceptable level.

We let each $L_{j}$ be constrained by $L_{j} \leq L$, where $L$ is a positive integer. It is not necessary to use a very large $L$, since ambulances that become busy will be available again when they have completed their call. Suppose, for example, that the three closest ambulances in a specific case are located at 
5, 10 and 15 minutes respectively from zone 23 and that $\gamma^{l}=1,0.5,0.25$ for $l=1,2$, 3 . With a demand, $c_{23}$, equal to 0.1 , this would give a preparedness of $p_{23}=(1 / 0.1) *(1 / 5+0.5 / 10+0.25 / 15) \approx 2.67$. However, the value 2.67 does not tell us anything if it cannot be put into a context, which is characteristic for most index measures. Thus, we need a calibration and a validation procedure to find relevant values for the parameters and to make sure that the measure is useful.

\subsubsection{Validation of the measure}

As for the final step in the methodology, the preparedness measure is validated using three different methods:
A. Comparison with coverage measures
B. Validation by simulation
C. Validation by dispatcher evaluation

First, the measure is calibrated for the county of Stockholm in Sweden. The area is divided into 1240 zones, and a travel time matrix is produced containing deterministic travel times from each zone to each other zone. Population data for each zone is used to calculate $c_{j} \cdot \gamma^{l}$ is set to $1 / 2^{l-1}$ for $l=$ $1,2, \ldots, 7$, i.e. $\gamma^{1}=1, \gamma^{2}=0.5, \gamma^{3}=0.25, \gamma^{4}=0.125$, etc. A maximum of 7 ambulances are used to calculate the preparedness for a zone. The objective in Method A is to see if the measure behaves similar to other preparedness measures, in this case coverage. Thus, we would like to see that for increasing values on $p_{j}$, we also get an increase in the coverage.

Coverage is calculated as the number of people (in percent) that can be reached by one ambulance, within 10, 15 and 20 minutes respectively. This makes coverage a measure for the entire area, while the preparedness is calculated per zone. Therefore we define the area preparedness $\mathrm{P}$ as:

$P=\min _{j \in N} p_{j}$

where $\mathrm{N}$ is the set of zones. Other ways of aggregating the zone preparedness values into area preparedness are discussed in Lee (2011). A mathe- 
matical model is formulated to maximize the area preparedness $P$, and solutions for a number of test cases involving a varying set of ambulances are obtained using a simulated annealing heuristic. The coverage is calculated for the resulting location solutions and the result can be seen in Figure 3.1. It is clear that the coverage in the area increases when the area preparedness $P$ increases.

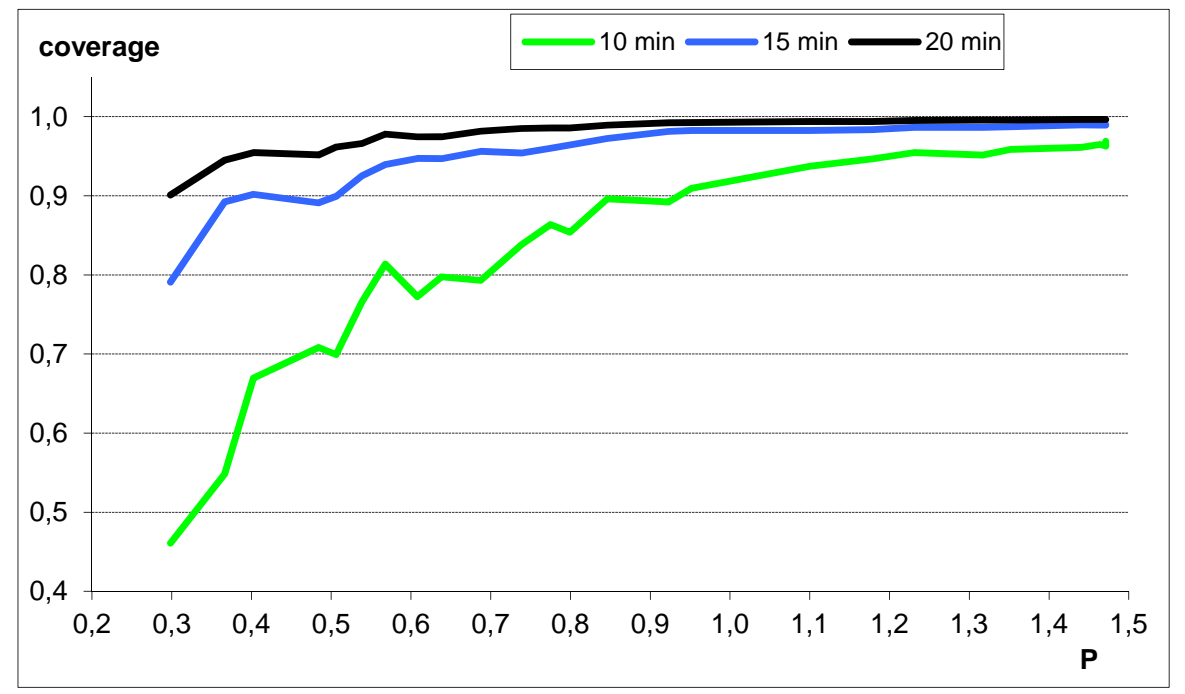

Fig. 3.1. The coverage increases when the area preparedness increases

The results from validation method A indicate that the construction of the preparedness measure, and the parameter settings, make sense when compared to coverage. It should be noted that the coverage measure used here only include first response coverage, and does not take into account the possibility that an ambulance might become busy, something that is built into $p_{j}$.

Method B involves validating the preparedness measure using simulation. Using the measure as a base, an ambulance dispatch algorithm and a relocation algorithm are developed. The ambulance dispatch algorithm will dispatch the closest ambulance for all priority 1 calls (life threatening). When faced with less urgent calls, the algorithm will select all ambulances that are reasonably close (e.g. within 20 minutes) to the call site, and recalculate the preparedness in all zones given that one of these ambulances are 
dispatched. Finally, the ambulance that has the least impact on the area preparedness will be dispatched.

The ambulance relocation problem occurs when one or more zones have a preparedness level less than a certain threshold, $P_{\min }$. The objective is then to reach the $P_{\min }$ level in all zones as quickly as possible. The preparedness is increased by relocating one or more ambulances closer to the zones that suffer from a low level of preparedness. The relocation problem is solved using a greedy tree search heuristic.

Both algorithms are incorporated into a simulation model which is run using the same data (although somewhat refined, especially the demand data) as in Method A. The results show that the response times decrease with more sophisticated dispatching (when evaluating the preparedness before dispatching to low priority calls, instead of just sending the closest ambulance) and when using relocations. However, a lot of relocations are needed to get significant reductions in response time. More details on the validation work using Method B can be found in Andersson and Värbrand (2007).

The results from Method B indicate that if the preparedness measure is used practically, the main performance parameter in EMS - the response times (or more accurately the patient waiting times) - should benefit. The preparedness measure can be implemented into a geographical information system (GIS), visualizing zones with preparedness less than $P_{\min }$ as red. The dispatchers can then manually act upon this information and take it into account when selecting units to dispatch, or trigger relocations to preserve the preparedness in the area.

In Method C, the main users of the EMS preparedness index, i.e. the ambulance dispatchers, gets to evaluate the measure. The preparedness measure, with a corresponding visualization feature, the dispatcher algorithm and the relocation algorithm, are implemented in the GIS used in emergency centers in Sweden, operated by the company SOS Alarm. 11 scenarios are constructed, where in each scenario, 3-6 areas are marked. The scenarios consist of a map screenshot from the GIS with a set of available ambulances, the day and the time. 20 dispatchers, who all have experience of 
working with the areas in the scenarios, have to decide if the preparedness in each area is good (1) or bad (0). The result is shown in Figure 3.2. It is obvious from the result that different ambulance dispatchers may have different opinions regarding EMS preparedness. Dispatcher 4 (Op4) thinks that the preparedness is less than acceptable in 37 of the 48 areas, while dispatcher 11, 14 and 16 only think it is bad in six areas. Not for one single area, the dispatchers agree that the preparedness is inadequate; even for the worst area (Area 8-2) one dispatcher (Op2) considers the preparedness to be acceptable. However, the preparedness is considered good enough by all the dispatchers in ten of the 48 areas.

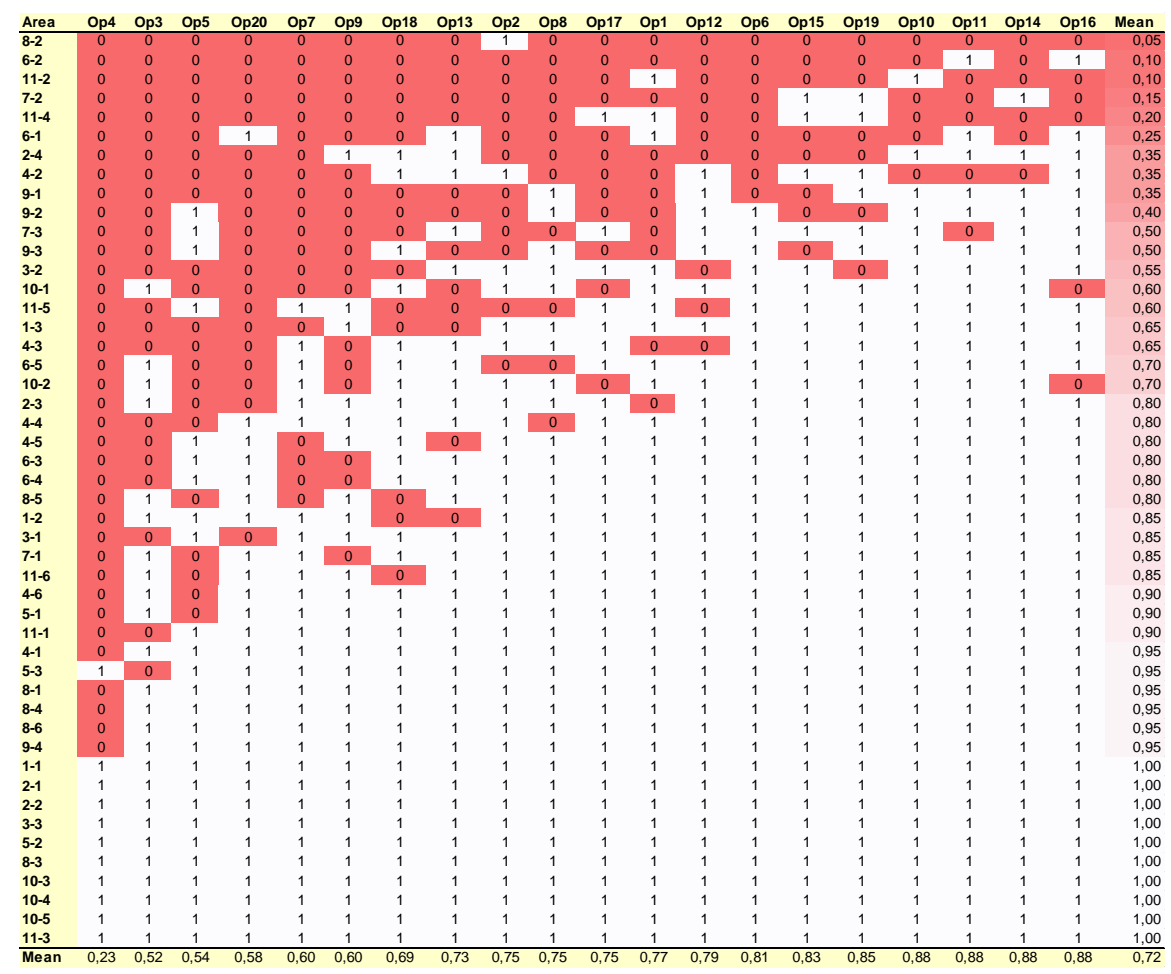

Fig. 3.2. Dispatcher perception regarding EMS preparedness

The preparedness $p_{j}$ for the areas are calculated for different choices of parameters and are compared to the mean values of the dispatchers' results. The parameter settings that are tested include different values on $\gamma$ as well as the squaring of the travel times. Comparing the dispatchers perception 
of what entails EMS preparedness, with the values that are produced by the quantitative measure, reveals that using contribution factors $\gamma=1,0.5$, 0.25 , etc. reduce the contribution from the second and the third ambulance too quickly. Thus, for an area with high demand, it might never be possible to reach an adequate preparedness level, no matter how many ambulances that are available. Contribution factors $\gamma=1,0.9,0.8$, etc. give a better correspondence to how the ambulance dispatchers perceive preparedness. Another result of Method C is that by squaring the travel times, i.e. using a measure like:

$p_{j}=\frac{1}{c_{j}} \sum_{l=1}^{L_{j}} \frac{\gamma}{\left(t_{j}^{l}\right)^{2}}$

the preparedness measure is enhanced even further. This becomes evident when studying some of the areas where the preparedness measure fails, and realizing that it is because there are two or three ambulances at some distance (e.g. 30 minutes) from a fairly, not overly, demand intensive area. The preparedness measure without the squared travel times will then calculate the preparedness as adequate, since the ambulances together make up a good preparedness. A majority of the dispatchers, on the other hand, would like to have at least one ambulance closer to the area for the preparedness to be adequate. One option to mirror the dispatchers' opinions in this case is to lower the threshold level, $P_{\text {min }}$, until the preparedness is low in this area as well, but this will result in a low preparedness also in high demand areas, that actually have plenty of ambulances nearby. By squaring the travel times, the preparedness will drop rapidly when the ambulances are further away. This way, it is possible for multiple ambulances to build up a good preparedness in areas where the demand is high, by being located close to that area. However, the preparedness in areas with a medium demand and no ambulances close by will be inadequate, just like the dispatchers perceive it.

The next logical step in the validation process would be to repeat Method A and B with the new preparedness measure and the new parameter settings, to ensure that these results still hold. Furthermore, the dispatcher 
evaluation should be repeated with dispatchers from other emergency centers, working with other geographical areas.

The method proposed in Section 2 can thus be used to develop a preparedness measure for emergency medical services, focusing on daily events. Similarly, it is possible to construct a measure for e.g. fire and rescue services. However, this would have to take into account that the events considered might differ quite a lot in regards to which and how many resources that are needed in the response.

\section{Conclusion}

This chapter gives an introduction to the concept of measuring preparedness, and an overview of the methods available. It is easy to convince someone that it is beneficial to measure preparedness, risk and vulnerability, but most of the preparedness measures available have a clear disadvantage. They do not say anything by themselves, they lack units and they are difficult to understand and interpret. Both of the preparedness measures presented in more detail in this chapter are unit-less, and the preparedness needs to be calculated for number of counties (in the hurricane measure) or for a number of zones (in the EMS case). When this has been done, it is possible to compare different counties or zones, and define a level of standard for the preparedness.

What would be useful for a decision maker is a measure that can be applied without the need for benchmarking. But then the measure would have to have a unit that can easily be interpreted, e.g. cost or expected number of lives lost. The main difficulty with constructing such a measure is the complex relations between the event, the response, the vulnerability, and the consequences. It is extremely difficult to say, with some certainty, how many people in a specific city that will die in an earthquake. It is even more difficult to say how many that will be saved with the introduction of an early warning alarm system, or if the number of emergency response resources are increased by $10 \%$. Even for systems dealing with everyday accidents, where historical data is available, this is not trivial. Consider for 
example a housing fire. The consequence of the fire can be measured in lives lost, people injured, property value destroyed, and environmental damages. However, how many lives that are lost will depend on how many people that were inside when the fire started (which is correlated to the time of day), the material and the construction of the house, how quickly the fire services arrive, how many firefighters that respond, which kind of vehicles and equipment they have, and many other factors. This makes it difficult to find a model that can predict the consequences given that we have all the input values, though such a model would very useful.

Consequently, there is need for more research investigating the relations between emergencies, disaster and other events, the preparedness for handling them, and the consequences. Given that we can find, and quantify these relations, it will - to a much larger extent - be possible to measure and optimize the preparedness, and also get acceptance for the results.

\section{References}

Andersson T, Petersson S, Värbrand P, (2007), Decision support for efficient ambulance logistics. In Brailsford S \& Harper P (eds), “Operational Research For Health Policy: Making Better Decisions - Proceedings of the 31st Annual Conference of the European Working Group on Operational Research Applied to Health Services”, Peter Lang Publishing Group, 2007, $107-126$.

Andersson T, Värbrand P, (2007), Decision support tools for ambulance dispatch and relocation. Journal of the Operational Research Society, 58(2), 2007, 195-201.

Baker EJ, (2011), Household preparedness for the Aftermath of Hurricanes in Florida. Applied Geography, 31(1), 46-52.

Birkmann J, (2007), Risk and vulnerability indicators at different scales: Applicability, usefulness and policy implications. Environmental Hazards, 7, 20-31.

Cardona OD, (2005), Indicators of disaster risk and risk management -main technical report, IDB/IDEA Program of Indicators for Disaster Risk Management, National University of Colombia, Manizales.

Collins English Dictionary - Complete and Unabridged, (2003), HarperCollins Publishers.

Davidson RA, Lambert KB, (2001), Comparing the hurricane disaster risk of U.S. coastal counties. Natural Hazards Review, 2(3), 132-142.

Haimes YY, Crowther K, Horowitz BM, (2008), Homeland Security Preparedness: Balancing Protection with Resilience in Emergent Systems. Systems Engineering, 11(4), 287-308.

Lee S, (2011), The role of preparedness in ambulance dispatching. Journal of the Operational Research Society, 62, 1888-1897.

Manca D, Brambilla S, (2011), A methodology based on the Analytic Hierarchy Process for the quantitative assessment of emergency preparedness and response in road tunnels. Transport Policy, 18, 657-664. 
Markenson D, Krug S, (2009), Developing Pediatric Emergency Preparedness Performance Measures. Clinical Pediatric Emergency Medicine, 10(3), 229-239.

Rachmalia MNS, Urai Hatthakit RN, Aranya Chaowalit, APN, (2011), Tsunami preparedness of people living in affected and non-affected areas: A comparative study in coastal area in Aceh, Indonesia. Australasian Emergency Nursing Journal, 14(1), 17-25.

Sargent R., (2005) Verification and validation of simulation models, in Proceedings of the 2005 Winter Simulation Conference, 130-143.

Simpson D, (2008), Disaster preparedness measures: a test case development and application. Disaster Prevention and Management, 17(5), 645-661.

UNISDR (2011), http://www.unisdr.org/we/inform/terminology. The secretariat of the International Strategy for Disaster Reduction, accessed 2011-10-13.

WHO, (2011), Comparative analysis of national pandemic influenza preparedness plans. World Health Organization. 